and the qualifications for membership are a degree or equivalent in engineering for the C.Eng., a Higher National Certificate or City and Guilds Full Technological Certificate for a T.Eng. (CEI) and an Ordinary National Certificate or a City and Guilds Part II Final Technicians Certificate for a Tech.(CEI). Membership also requires appropriate training and experience in all categories.

The C.Eng. qualification is not new and was first instituted when the Council of Engineering Institutions was formed in 1965. The two new classes now instituted will, it is hoped, supersede 50 or 60 titles that have been in use for many years all with different qualification standards. Whereas the Council of Engineering Institutions does not expect all engineers to apply for membership immediately, a spokesman said this week that the eventual goal is to have the presently instituted qualifications accepted as the standard by all British engineers.

Engineers can be nominated to the register by one of the fifteen constituent members of the ERB. There will be no fee directly paid to the board by the engineer-his membership of the parent institution will be sufficient to qualify for membership. The member institutions are enthusiastic about the setting up of the Engineers' Registration Board, but as yet they have not tended to approach their corporate members to ask their views. There seems to be no reason why members should not share this view.

\section{SCIENCE MUSEUMS}

\section{Summer Boom in London}

IN the summer months, attendance at the London museums reaches its annual peak and the Science Museum and the Natural History Museum-the British Museum (Natural History) as it calls itself-is sharing in the popularity. The Science Museum has had more than $2,000,000$ visitors a year since 1968 and the Natural History Museum has some $1,500,000$ visitors a year-a figure that is increasing at 10 per cent a year.

But who comes to the museums, and what do they offer? There are no detailed statistics, although a survey that would establish this has been suggested at the Central Office of Informationbut both museums know they have to cater for large numbers of children. The Natural History Museum has it down to a considerable art, with a special Children's Centre open on Saturdays during term and six days a week during school holidays. This helps children to find their way constructively around the museum by providing them with "Nature Trails" and encouraging those showing a genuine interest to join the Natural History Club which meets on Saturdays, when a certain amount of field work is done. There are close links with schools and teachers, and school parties are frequent. From a small random survey last winter, the Natural History Museum has some idea of the age distribution of its visitors- 65 per cent of them are under thirty, over half of those are under twenty, and the survey excluded school parties, which provided just under 120,000 visitors in 1970 .

The Science Museum has no such figures, but it thinks that one third of its visitors are children and that an appreciable proportion of them come time and again. Arrangements for seriously interested children are meagre, although the museum does run an increasingly comprehensive and varied set of lectures and tours. There is no equivalent of the "Nature Trails" - an experiment with a similar scheme is said to have turned out to be administratively and technically unmanageable. There is, however, some contact with schools and the special Children's Gallery, transferred to a larger location in the basement some two years ago, is as popular as ever. The transfer has allowed for several new exhibits to be included together with the old favourites.

Since 1963, the work of modernizing the exhibitions has progressed gallery by gallery, for the museum is aware that even if new exhibits are continually installed, the design of a gallery dates over the years. A spokesman said that plans are also afoot to redesign the mathematics gallery to include information on computing-a feature that has been sadly neglected to date-with the possibility of a working computer terminal. A section on production engineering is also planned, and both schemes should increase the topicality of the museum

Although the museum itself makes no complaint, the sum available for new acquisitions is only $£ 8,000$ a year, a frighteningly small amount of money if the museum is expected to keep any sort of pace with scientific and technological developments. In spite of the attraction for children in the many working models, the museum does not consider itself primarily for children. They feel that their research facilities are an important part of their work, and that the main aim of the public galleries is to arouse people's curiosity, and possibly stimulate them to a deeper interest.

The Natural History Museum fills rather a different role from the Science Museum. Despite its large public halls, its purposes lie rather in the fields of active research, which the new wing, and the new building at Tring, at present under construction, will help to further. Established in 1881 on a taxo- nomical basis, the museum is now questioning the validity of this as current research shows more and more that animals and organisms should be considered in their environments, and a spokesman said there may be changes in the future to base the layouts on ecological principles. Before this can be fully accomplished more exhibition space will be needed.

Nevertheless the main purpose of the museum is always likely to be one of research, partly because of the impossibility of displaying more than a small percentage of the natural world-for example the museum owns some 250,000 mineral specimens alone, of which only 4 per cent are on displayand partly because there is much still to be made known about the natural world. After all, although there are some 750,000 known species of insects, it is estimated that there are between two and four times as many yet to be identified.

\section{CONSERVATION}

\section{Just for the Birds}

The Royal Society for the Protection of Birds has recently established a 335 acre reserve in the Dale of Cottascarth on the mainland of Orkney. The society, which manages more than forty other bird sanctuaries throughout the British Isles, chose this northern site because there are a number of typical habitats of the birds that breed in Orkney within its boundaries. These reserves are an attempt to maintain the natural integrity of wildlife communities and those that have been in existence for some time have been very successful in this purpose. Access is restricted to members of the society, although this year saw the well established reserves open their doors a fraction to let in small numbers of the interested public. The doors are unlikely to open much wider, and understandably so for the birds' sake.

With the ever-increasing popularity of Orkney with holiday-makers, the establishment of the Cottascarth reserve is wise and timely. The Dale is, in fact, scheduled by the Nature Conservancy as a site of special botanic interest.

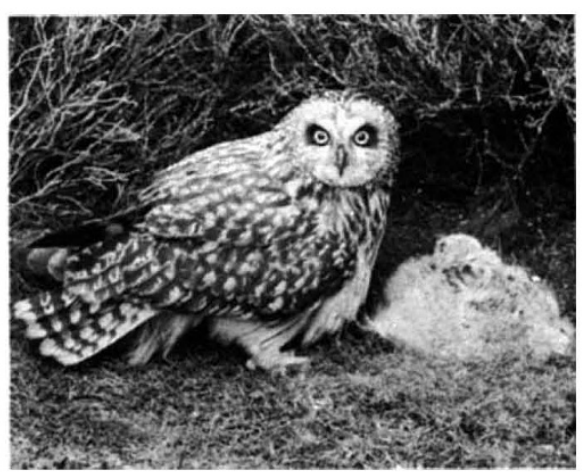

Short-eared owl with young. 